\title{
CURRENT ACCOUNT EFFECTS OF CENTRAL BANKING
}

Tobias Duemmler, Darmstadt University of Technology, Darmstadt, Germany

Stephan Kienle, Darmstadt University of Technology, Darmstadt, Germany

dx.doi.org/10.18374/IJSM-13-2.1

\begin{abstract}
We enlarge the absorption approach of the current account by taking the German central bank's contribution to the capital account explicitly into account. Within a VECM approach we reveal a relationship between several variables of interest, among them German net exports as well as the Bundesbank's net claims within the Eurosystem. In line with intuition, an increase in net claims seems to be positively related to the current account.
\end{abstract}

Keywords: Current Account; Central Bank Net Claims; Cointegration 